\title{
Climatology of GPS phase scintillation and HF radar backscatter for the high-latitude ionosphere under solar minimum conditions
}

\author{
P. Prikryl ${ }^{1}$, P. T. Jayachandran ${ }^{2}$, S. C. Mushini ${ }^{2}$, and R. Chadwick ${ }^{2}$ \\ ${ }^{1}$ Communications Research Centre, Ottawa, ON, Canada \\ ${ }^{2}$ Physics Department, University of New Brunswick, Fredericton, NB, Canada
}

Received: 24 November 2010 - Revised: 14 February 2011 - Accepted: 15 February 2011 - Published: 22 February 2011

\begin{abstract}
Maps of GPS phase scintillation at high latitudes have been constructed after the first two years of operation of the Canadian High Arctic Ionospheric Network (CHAIN) during the 2008-2009 solar minimum. CHAIN consists of ten dual-frequency receivers, configured to measure amplitude and phase scintillation from L1 GPS signals and ionospheric total electron content (TEC) from L1 and L2 GPS signals. Those ionospheric data have been mapped as a function of magnetic local time and geomagnetic latitude assuming ionospheric pierce points (IPPs) at $350 \mathrm{~km}$. The mean TEC depletions are identified with the statistical high-latitude and mid-latitude troughs. Phase scintillation occurs predominantly in the nightside auroral oval and the ionospheric footprint of the cusp. The strongest phase scintillation is associated with auroral arc brightening and substorms or with perturbed cusp ionosphere. Auroral phase scintillation tends to be intermittent, localized and of short duration, while the dayside scintillation observed for individual satellites can stay continuously above a given threshold for several minutes and such scintillation patches persist over a large area of the cusp/cleft region sampled by different satellites for several hours. The seasonal variation of the phase scintillation occurrence also differs between the nightside auroral oval and the cusp. The auroral phase scintillation shows an expected semiannual oscillation with equinoctial maxima known to be associated with aurorae, while the cusp scintillation is dominated by an annual cycle maximizing in autumn-winter. These differences point to different irregularity production mechanisms: energetic electron precipitation into dynamic auroral arcs versus cusp ionospheric convection dynamics. Observations suggest anisotropy of scintillationcausing irregularities with stronger L-shell alignment of irregularities in the cusp while a significant component of
\end{abstract}

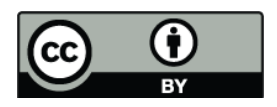

Correspondence to: P. Prikryl (paul.prikryl@crc.gc.ca) field-aligned irregularities is found in the nightside auroral oval. Scintillation-causing irregularities can coexist with small-scale field-aligned irregularities resulting in HF radar backscatter. The statistical cusp and auroral oval are characterized by the occurrence of HF radar ionospheric backscatter and mean ground magnetic perturbations due to ionospheric currents.

Keywords. Ionosphere (Ionospheric irregularities) - Radio science (Space and satellite communication; Instruments and techniques)

\section{Introduction}

The spatial and temporal variability of the high-latitude ionosphere depend on many variables that include local time and season, magnetic latitude and magnetic local time, solar and geomagnetic activity. The dependence of total electron content (TEC) and scintillation intensity on these factors has been recognized and studied at VHF/UHF frequencies for many years (Aarons, 1982; Basu et al., 1987; Kersley et al., 1988; Gola et al., 1992). More recently, GPS receivers have improved coverage at high latitudes (Aarons, 1997; Aarons et al., 2000; Mitchell et al., 2005; Alfonsi et al., 2008; Jayachandran et al., 2009; Spogli et al., 2009; Yin et al., 2009; Li et al., 2010).

Early scintillation studies that were typically limited to intensity scintillation characterized by intensity (amplitude) fading or $S_{4}$ index (Aarons, 1982) noted seasonal and diurnal variations of scintillation at all latitudes, including the auroral zone and the polar region. In the auroral zone it was shown that VHF/UHF scintillation activity was high even when geomagnetic conditions were quiet. Diurnal and seasonal patterns with maxima around local midnight and in the spring (March to May) were found (Aarons, 1982; Basu, 1975). The occurrence of amplitude and phase scintillation

Published by Copernicus Publications on behalf of the European Geosciences Union. 


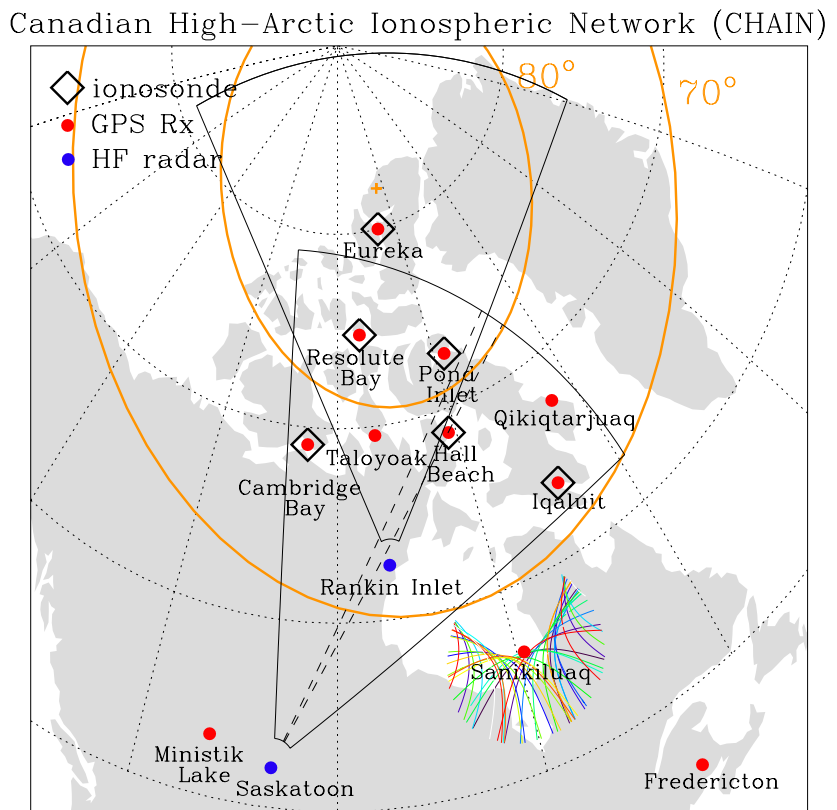

Fig. 1. Canadian High Arctic Ionospheric Network (CHAIN). The loci of ionospheric pierce points (IPPs) at $350 \mathrm{~km}$ altitude for all GPS satellites as seen from Sanikiluaq at elevation angles above $30^{\circ}$ during one day are shown. The corrected geomagnetic (CGM) latitudes $70^{\circ}$ and $80^{\circ}$ and fields of view of two SuperDARN radars are superposed over the geographic grid. Beam 8 for the Saskatoon radar that is used in the statistical study is shown with dashed line.

was found to be particularly elevated on the dayside in the cusp/cleft region, showing variations with season and magnetic activity (Kersley et al., 1988, 1995; MacDougall, 1990a, b; Gola et al., 1992). In the polar cap, amplitude scintillation exhibited clear seasonal and UT variation, which was consistent with mesoscale plasma density modeling results (Basu et al., 1995; Sojka et al., 1994).

The Canadian High-Arctic Ionospheric Network (CHAIN) is an array of Global Positioning System (GPS) receivers and ionosondes (Jayachandran et al., 2009) for studying ionospheric structure at high temporal resolution and spatial scales from $1000 \mathrm{~km}$ down to a few hundred meters at high latitudes. Such structuring gives rise to irregularity causing scintillation, rapid fluctuations of radio signal amplitude and phase that may affect performance of radio communication and navigation systems. CHAIN is supported by radars, optical instruments and magnetometers, most of which are part of the Canadian GeoSpace Monitoring (CGSM) program (Liu, 2005; Mann et al., 2008).

In this paper the data from the first two years of CHAIN operation contribute to the climatology of phase scintillation at high latitudes under solar minimum conditions. The results are supported by a statistical analysis of occurrence of F-region decameter irregularities monitored with HF radars of the SuperDual Auroral Radar Network (SuperDARN) and by magnetometers recording the perturbation of the ground magnetic field due to ionospheric currents.

\section{Instruments and data}

The current CHAIN instruments (Jayachandran et al., 2009) are ten specialized GPS receivers and six Canadian Advanced Digital Ionosondes (CADIs) distributed in the auroral oval and the polar cap (Fig. 1). One GPS receiver was temporarily operated in Fredericton, New Brunswick $\left(49.95^{\circ} \mathrm{N}\right.$, $293.36^{\circ} \mathrm{E}$ ) from January to August 2008. Table 1 lists the geographic and corrected geomagnetic coordinates of the CHAIN stations. The collocation of six of the ten GPS receivers with ionosondes (MacDougall et al., 1995) will have an added advantage in the tomographic imaging of the electron density structures in the polar cap and the calibration of the GPS data. This configuration will allow us to perform more realistic 3-D tomographic inversions of the ionosphere using the Multi-Instrument Data Analysis System MIDAS (Mitchell and Spencer, 2003) or the Global Assimilative Ionospheric Model - GAIM (Hajj et al., 2004) than tomographic reconstructions that rely on statistical ionospheric models.

The CHAIN GPS receivers are the GPS Ionospheric Scintillation and TEC monitors (GISTM) GSV 4004B (Van Dierendonck and Arbesser-Rastburg, 2004). GISTM consists of a NovAtel OEM4 dual frequency receiver with special firmware specifically configured to measure and log power and phase of the GPS L1 signal at high sampling rate $(50 \mathrm{~Hz})$. The receiver computes ionospheric TEC from the GPS L1 and L2 signals. The GSV 4004B can also automatically compute and record the amplitude scintillation index, $S_{4}$, which is the standard deviation of the received power normalized by its mean value, and the phase scintillation index $\sigma_{\phi}$, the standard deviation of the detrended phase using a filter in the receiver with $0.1 \mathrm{~Hz}$ cutoff. This receiver is capable of tracking and reporting scintillation and TEC measurements simultaneously from up to 10 GPS satellites in view (Jayachandran et al., 2009). The collected GPS and CADI data are transferred to the University of New Brunswick CHAIN data center in near-real-time basis using satellite links (TELESAT - Ka Band). Data can be accessed and displayed through an interactive interface available at http://chain.physics.unb.ca/chain.

The $S_{4}$ index and the phase scintillation index $\sigma_{\phi}$ used in this paper are computed for 60 -s intervals. Continuous GPS data collection started in summer 2008, except for GPS receivers in Cambridge Bay and Ministik Lake, which operated since December 2007, and the temporary operation in Fredericton from January to August 2008. All available GPS data from 2008 to 2009 are used in the statistical analysis. A minimal elevation of $30^{\circ}$ is used to reduce the impact of nonscintillation related tracking errors such as multipath. Following the procedure adopted by Spogli et al. (2009; their Eqs. 1 and 2), scintillation indices are projected to the vertical to account for geometrical effects on the measurements made at different elevation angles. 
Table 1. Geographic and corrected geomagnetic coordinates of the CHAIN stations.

\begin{tabular}{lrrrr}
\hline Station & $\begin{array}{r}\text { Geographic latitude } \\
\left({ }^{\circ} \mathrm{N}\right)\end{array}$ & $\begin{array}{r}\text { Geographic longitude } \\
\left({ }^{\circ} \mathrm{E}\right)\end{array}$ & $\begin{array}{r}\text { Corrected geomagnetic } \\
\text { latitude }\left({ }^{\circ} \mathrm{N}\right)\end{array}$ & $\begin{array}{r}\text { Corrected geomagnetic } \\
\text { longitude }\left({ }^{\circ} \mathrm{E}\right)\end{array}$ \\
\hline Eureka (EUR) & 79.99 & 274.10 & 88.10 & 329.86 \\
Resolute Bay (RES) & 74.75 & 265.00 & 83.13 & 320.61 \\
Pond Inlet (PON) & 72.69 & 282.04 & 81.67 & 0.69 \\
Cambridge Bay (CAM) & 69.12 & 254.97 & 77.24 & 310.11 \\
Taloyoak (TAL) & 69.54 & 266.44 & 78.75 & 329.70 \\
Hall Beach (HAL) & 68.78 & 278.74 & 78.33 & 353.45 \\
Qikiqtarjuaq (QIK) & 67.53 & 295.97 & 75.77 & 22.57 \\
Iqaluit (IQA) & 63.73 & 291.46 & 72.85 & 14.04 \\
Sanikiluaq (SAN) & 56.54 & 280.77 & 67.19 & 356.44 \\
Ministik Lake (MST) & 53.35 & 247.03 & 61.50 & 307.57 \\
Fredericton (FRE) & 45.95 & 293.36 & 55.81 & 13.40 \\
\hline
\end{tabular}

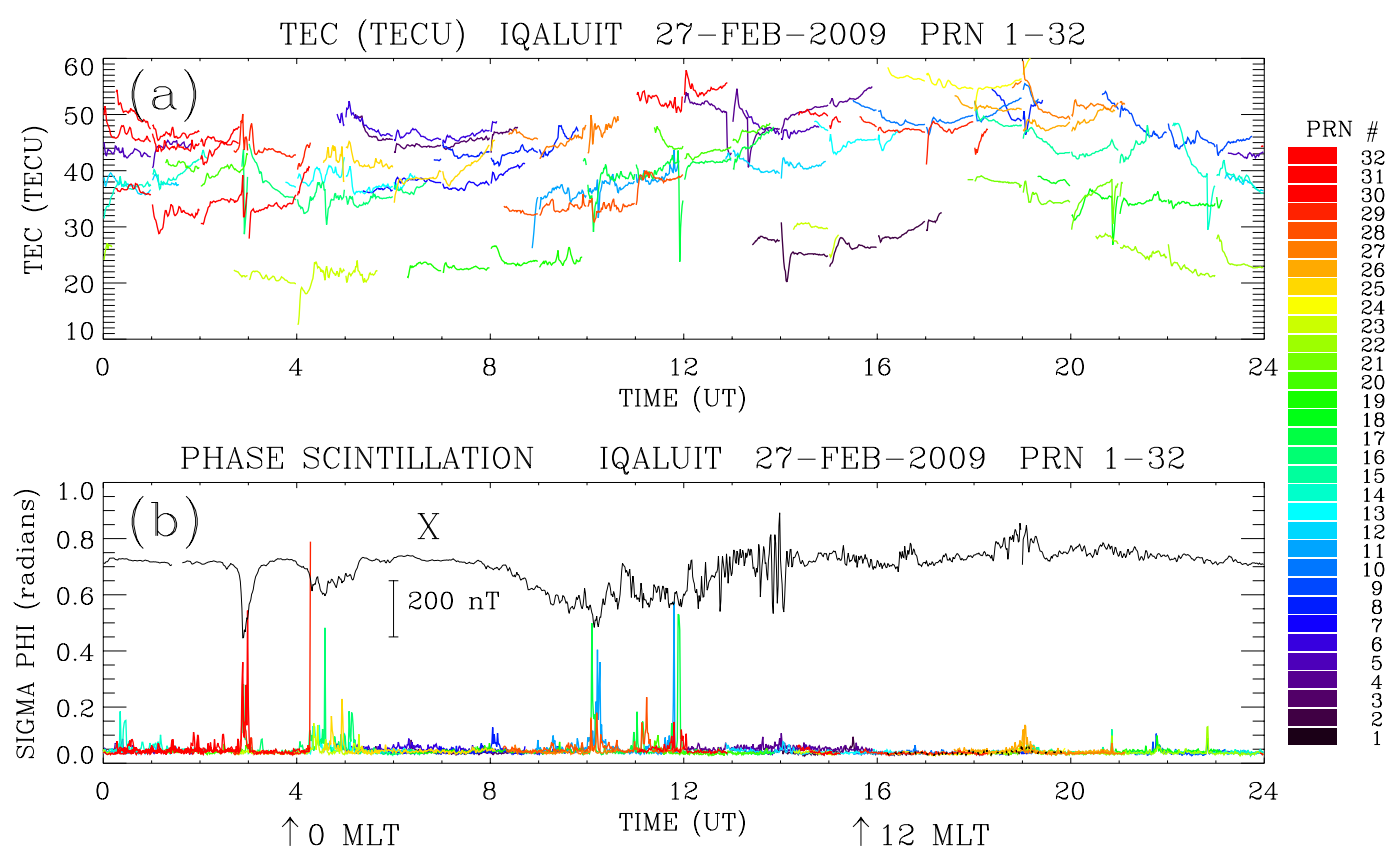

Fig. 2. (a) TEC and (b) phase scintillation index $\sigma_{\Phi}$ observed at elevations above $30^{\circ}$ from Iqaluit. The ground magnetic field X-component is superposed.

The Super Dual Auroral Radar Network (SuperDARN) is a network of coherent-backscatter HF radars with field of view covering a large fraction of the high-latitude ionosphere (Greenwald et al., 1995; Chisham et al., 2007). The radars transmit at frequencies $8-20 \mathrm{MHz}$ along 16 contiguous, successively swept azimuthal beams, each of which is gated into 75 range bins. The bins are $45 \mathrm{~km}$ long in standard operations, and the dwell time for each beam is $7 \mathrm{~s}$. A full 16-beam scan with successive beams separated by $3.24^{\circ}$ covers $\sim 52^{\circ}$ in azimuth every $2 \mathrm{~min}$. Several quantities including the line-of-sight Doppler velocity, spectral width and backscatter power from field-aligned ionospheric (FAI) plasma irregular- ities are routinely measured. The PolarDARN component of SuperDARN covers a large portion of the polar ionosphere in the Northern Hemisphere. The main objective of SuperDARN is to study ionospheric convection (electric fields) by observing the backscatter from FAIs, which drift in the $\boldsymbol{E} \times \boldsymbol{B}$ direction, where $\boldsymbol{E}$ and $\boldsymbol{B}$ are electric and magnetic fields, respectively. The Saskatoon radar field of view covers the entire high-latitude portion of CHAIN. The data from the Saskatoon (MLAT $61.34^{\circ} \mathrm{N}$ ) radar beam 8 pointing over Hall Beach and Pond Inlet are used in this study. 

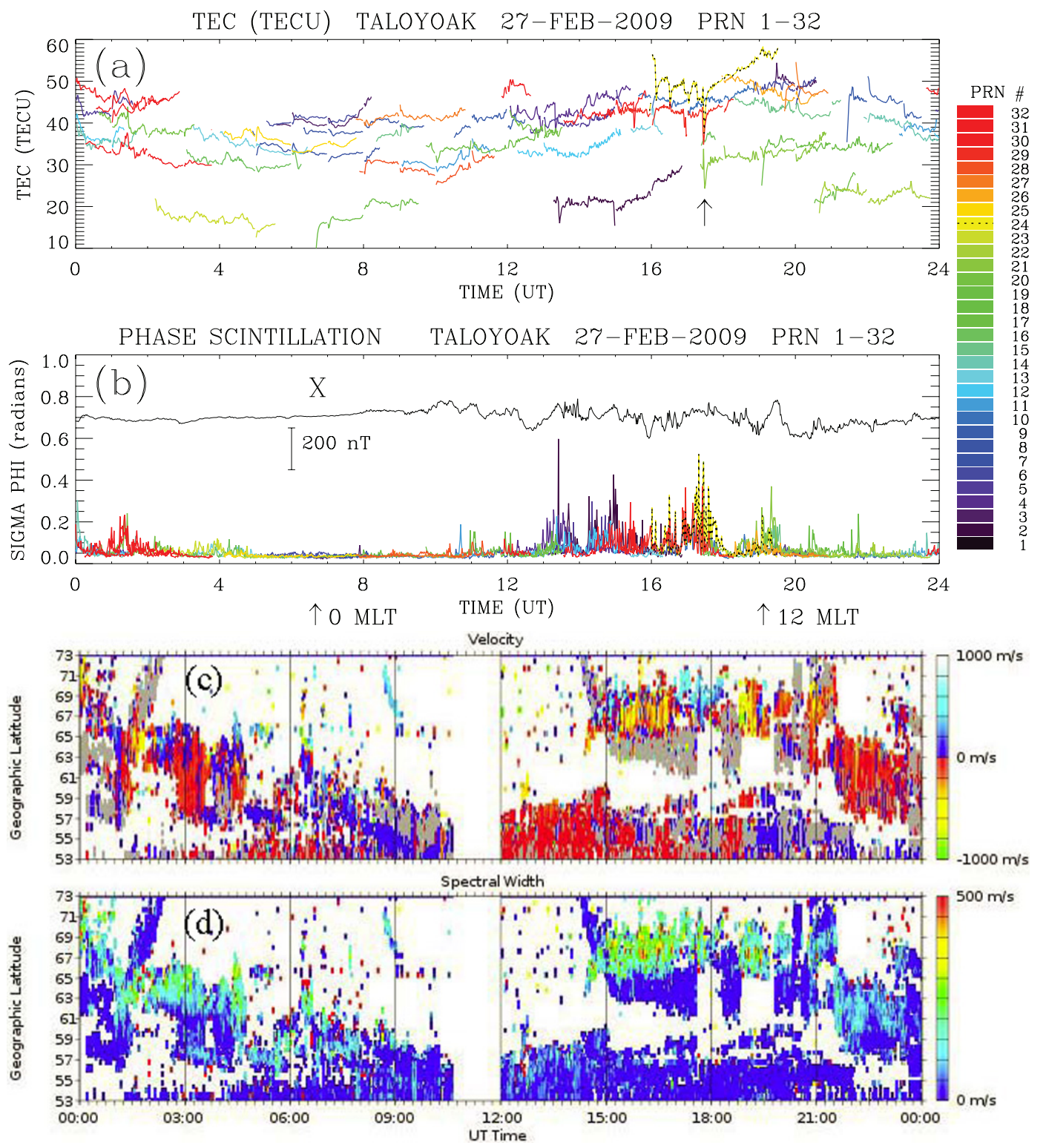

Fig. 3. (a) TEC, (b) phase scintillation index $\sigma_{\Phi}$ observed in Taloyoak, the Saskatoon radar beam-5 (c) line-of-sight velocity, and (d) spectral width. The arrow in the top panel points to a TEC depletion that was associated with the flow channel shown in Fig. 4 . The ground magnetic field $\mathrm{X}$ component is superposed.

\section{An example of TEC and phase scintillation observed in the auroral oval and cusp}

Before the presention of the climatology results, it is useful to illustrate the type of the data and their diurnal patterns obtained by CHAIN, magnetometers and HF radars in the geophysical context of one moderately disturbed event on 27 February 2009. High-speed solar wind from a coronal hole caused enhanced geomagnetic and ionospheric activity resulting in rapid TEC variations and phase scintillation in the auroral oval and poleward of it on the dayside in the cusp/cleft region. The scintillation was associated with an auroral arc and substorms in the nightside auroral oval and with enhanced dayside convection including flow channel events in the ionospheric footprint of the cusp, which can be identified by HF backscatter showing enhanced line-ofsight (LoS) velocities and spectral widths in the cusp (Baker et al., 1995). The cusp is the region through which tongue of ionization (TOI) is drawn into the polar cap (e.g., Foster et al., 2005) resulting in TEC enhancements and rapid TEC variations, which may cause cycle slips (Prikryl et al., 2010a, b).

Figure 2 shows TEC, phase scintillation index $\sigma_{\phi}$, and the ground magnetic field X-component in Iqaluit, where 


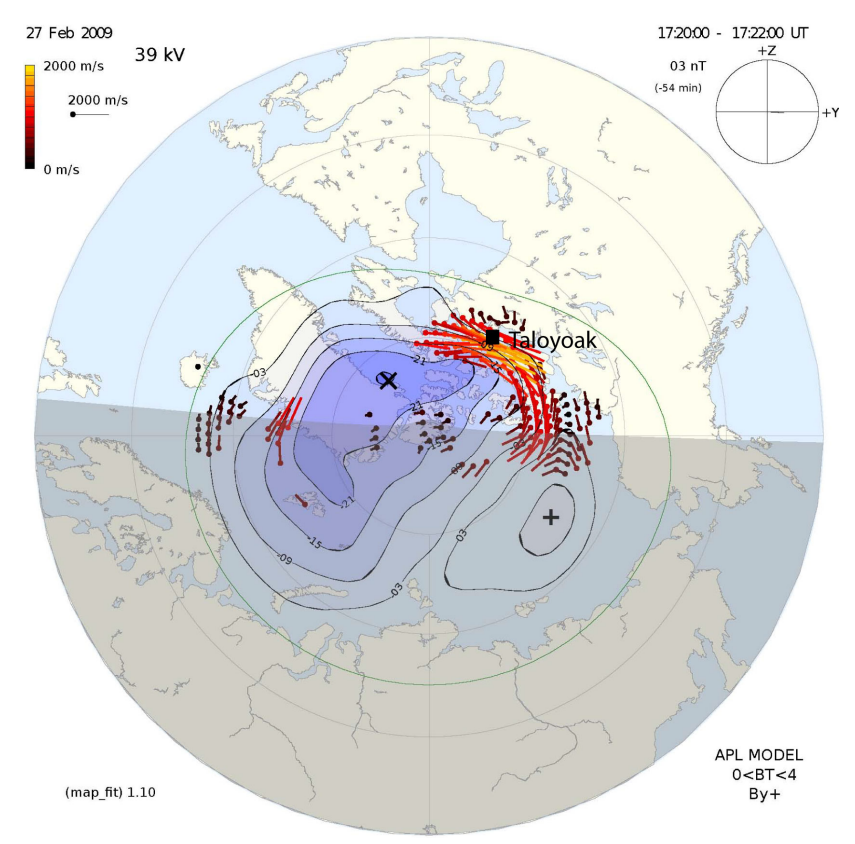

Fig. 4. SuperDARN convection map showing ionospheric flow enhancement in the cusp region at 17:20 UT. The map is in CGM coordinates with 12:00 MLT at the top.

the magnetic local midnight and noon were at 03:54 and 15:43 UT, respectively. The satellites are identified by the receiver by means of the pseudo random noise (PRN) numbers 1-32 color coded. Auroral substorm intensifications at $\sim$ 03:00 and between 04:00 and 05:00 UT were associated with enhanced $\sigma_{\phi}$ and perturbations in the TEC. Later in the morning sector after 09:00 UT, scintillation and TEC fluctuations occurred during an interval of enhanced geomagnetic Pc5 pulsations. At another auroral station in Sanikiluaq, phase scintillation was also coincident with geomagnetic activity associated with Pc5 pulsations observed by the ground magnetometer between approximately 09:00 and 11:00 UT (not shown). However, the amplitude scintillation $S_{4}$ index remained low, a result that has been reported previously (e.g., Ngwira et al., 2010). Low $S_{4}$ index is sometimes attributed to imprecise detrending methods, which in turn may lead to overestimation of phase scintillation indices compared to amplitude scintillation indices resulting in phasewithout-amplitude scintillation (Forte and Radicella, 2002; Forte, 2005, 2007; Mushini et al., 2010).

Figure $3 \mathrm{a}$ and $\mathrm{b}$ shows TEC, the phase scintillation index $\sigma_{\phi}$ and the ground magnetic field X-component in Taloyoak, where the magnetic local midnight and noon were at 06:37 and 19:04 UT, respectively. Moderate phase scintillation in the evening sector was associated with a bright auroral arc that was observed from 01:16 UT drifting poleward over the Taloyoak all-sky imager of the Northern Solar Terrestrial Array (NORSTAR) (Donovan et al., 2003). Just before the arc crossed the zenith at $\sim 01: 29 \mathrm{UT}$, the phase scintilla- tion peaked at $\sim 01: 20 \mathrm{UT}$ (Fig. 3b). However, the strongest scintillation in the pre-noon sector was associated with dynamic ionospheric convection and Pc5 pulsations particularly in the cusp/cleft. Figure $3 \mathrm{c}$ and d shows enhanced LoS velocity and spectral width (14:30-20:00 UT) observed by the Saskatoon radar beam 5 crossing the area where ionospheric pierce points (IPPs) for the Taloyoak GPS receiver are found. Enhanced LoS velocities and spectral widths were also observed by other SuperDARN radars in Rankin Inlet (13:00-20:00 UT) and Prince George (16:00-21:00 UT). Under the conditions of IMF $B_{\mathrm{y}}>0$, the SuperDARN convection maps (Fig. 4) showed quasi-periodic dayside ionospheric convection enhancements (westward flow channels) as a response to solar wind coupling at the magnetopause (Prikryl et al., 1999; see their Fig. 1). Such flow channels produce ionospheric plasma density depletions segmenting TOI into patches (Rodger et al., 1994; Foster et al., 2005). The GPS receiver in Taloyoak observed rapid TEC fluctuations and a series of quasi-periodic dips in TEC, which are attributed to density depletions. At 17:25 UT (see arrow in Fig. 3a), a sharp depletion that was observed in 3 PRNs (PRN \#24 coded yellow is highlighted by black dotted line) coincided with a flow channel shown in Fig. 4.

In general, the nightside phase scintillation typically appears to be episodic (Fig. 2b) and are localized to auroral precipitation events (auroral brightening; Prikryl et al., 2010a, b), while the cusp/cleft-related scintillation tends to be more continuous, with individual scintillation events lasting for several minutes per satellite but scintillation patches persisting over a larger geographical area sampled by different satellites for several hours (Fig. 3b). Although in both cases phase scintillation usually lasts only a few minutes per PRN, there is preponderance of longer durations, as well as of events occurring concurrently at different PRNs and receiver locations, in the cusp. To support this statement quantitatively, we define scintillation duration per PRN as the time that $\sigma_{\phi}$ stays continuously above threshold. A drop in $\sigma_{\phi}$ below an adopted threshold of 0.1 radians, even if only for one minute, marks the end of the event. For the example discussed in this section, only $3(13 \%)$ auroral scintillation events lasting 4-6 min were observed in Iqaluit between 02:00 and 06:00 UT, while on the dayside in Taloyoak, 33 (20\%) scintillation events lasting 4-21 min were observed between 13:00 and 20:00 UT. If weighted by the event duration, the percentages are in fact $34 \%$ and $52 \%$ for the auroral and cusp scintillation, respectively. Also, the number of PRNs concurrently affected during the cusp/cleft event in Taloyoak was much larger, thus indicating spatially extended scintillation. Statistics of scintillation duration are presented in the next section. 

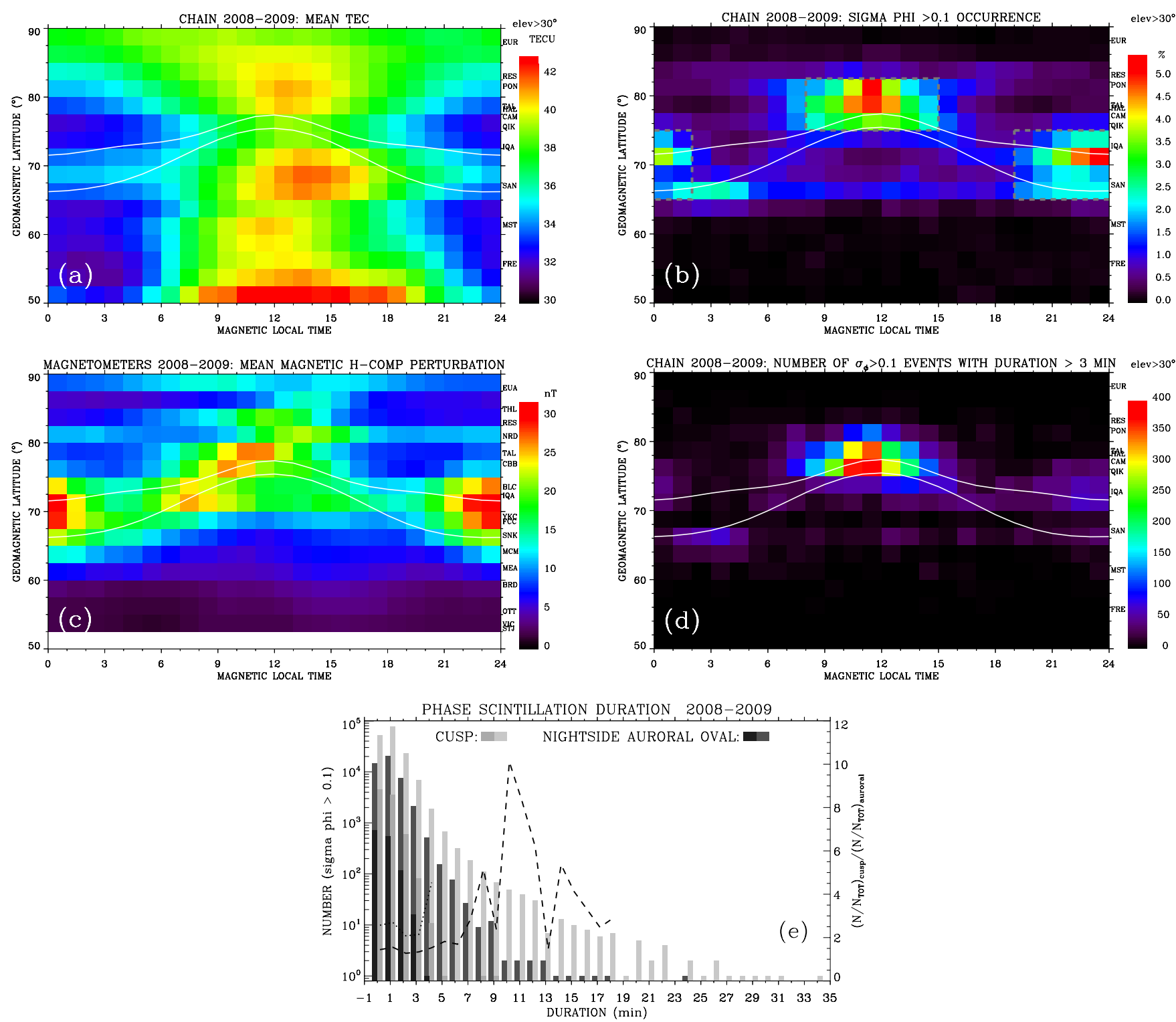

Fig. 5. Maps of (a) mean TEC, (b) phase scintillation occurrence, (c) horizontal component of the mean ground magnetic perturbations due to ionospheric currents, and (d) number of phase scintillation events lasting more than 3 min, as a function of MLT and CGM latitude. Superposed in white line is the Feldstein oval for $\mathrm{IQ}=2$. Superposed grey dashed rectangular bins in panel (b) indicate the regions representing the cusp and nightside auroral oval used when discussing seasonal variation and anisotropy of irregularities in Figs. 7 and 11 , respectively. (e) Number distribution of phase scintillation durations in the cusp and nightside auroral oval. The event numbers shown at 0 min represent all one-minute parts after the first minute for events longer than $1 \mathrm{~min}$. Darker shading shows events observed concurrently with 2 or more PRNs. Number ratio (on linear scale on the right side) of the cusp and auroral events normalized by the total number of data points is shown in dashed line. The dotted line shows the same ratio for events observed at multiple PRNs.

\section{TEC and phase scintillation climatology}

As indicated by the event discussed in Sect. 3, TEC and phase scintillation are functions of magnetic local time, geomagnetic latitude and the coupling between the solar wind and the magnetosphere/ionosphere system. To construct TEC and/or phase scintillation maps data have been ordered and binned by magnetic local time (MLT) and the Altitude
Adjusted Corrected Geomagnetic (AACGM) latitude (Baker and Wing, 1989). Assuming IPPs at $350 \mathrm{~km}$ altitude, the data are merged and the indices averaged into bins of $1 \mathrm{~h}$ MLT $\times 2.5^{\circ}$ CGM latitude. Before averaging, the observed 60 -s slant TEC values and phase scintillation indices are projected to the vertical, to account for varying elevation angles as discussed by Spogli et al. (2009). An elevation cutoff of $30^{\circ}$ and a threshold of 0.1 radians to obtain the 
percentage occurrence of phase scintillation are used. This low threshold is appropriate for solar minimum conditions and for intended comparison of phase scintillation and HF radar backscatter occurrence. Although higher threshold values reduce the occurrence percentages and the statistical significance, they give qualitatively similar results. The scintillation occurrence is defined as $100 \times N\left(\sigma_{\phi}>0.1\right) / N_{\text {tot }}$, where $N$ is the number of cases when phase scintillation index exceeded a given threshold and $N_{\text {tot }}$ is the total number of data points in the bin. Following the approach by Spogli et al. (2009) after Taylor (1997), we adopt the same criterion to remove the contribution of bins with poor statistics for which $R=100 \times \sigma\left(N_{\text {tot }}\right) / N_{\text {tot }}$ is greater than $2.5 \%$, where $\sigma\left(N_{\text {tot }}\right)=\sqrt{ } N_{\text {tot }}$ is the standard deviation of the number of data points in each bin. Such bins with sparse statistics are marked as grey areas in the plots.

Figure 5a-d shows the maps of mean TEC, the total percentage occurrence of phase scintillation with $\sigma_{\phi}$ exceeding 0.1 radians, number of continuous events lasting more than $3 \mathrm{~min}$, and mean horizontal ground magnetic perturbations due to ionospheric currents as a function of MLT and CGM latitude. Superposed on the maps are the boundaries of the Feldstein statistical auroral oval (Feldstein and Starkov, 1967) for quiet conditions (IQ=2) using the Holzworth and Meng (1975) parameterization. The latitudes of CHAIN stations or magnetometers are shown on the right. The CGM latitudes between $70^{\circ}$ and $85^{\circ}$ are clearly best covered with the CHAIN stations. However, considering the large spread of IPP latitudes for each station, the statistics are sufficiently high for all latitudes although it should be noted that only six months of data are available from Fredericton.

Uncalibrated TEC smoothed in latitude with a 3-point window is shown in Fig. 5a as a first qualitative result. A proper calibration procedure will be implemented in the future. Qualitatively, the dayside TEC is enhanced as expected but varies with latitude and MLT. The mean TEC (Fig. 5a) is highest at latitudes less than $55^{\circ}$, peaks also at dayside subauroral $\left(\sim 70^{\circ}\right)$ latitudes, and is enhanced from the cusp/cleft region to polar cap (poleward of $\sim 75^{\circ}$ ). These regions are separated by mean statistical troughs, namely the main (midlatitude) trough (Muldrew, 1965) centered at $\sim 60^{\circ}$ and the mean high-latitude trough at $\sim 75^{\circ} \mathrm{CGM}$ latitude, that are deepest just after midnight and that weaken towards noon.

The occurrence of phase scintillation is enhanced in the cusp/cleft (hereafter referred to as "cusp") and in the nighttime auroral oval indicated by grey dashed rectangles (Fig. 5b). Asymmetry about magnetic local noon and midnight is observed: there is higher occurrence of phase scintillation in pre-noon and pre-midnight hours. As already briefly discussed in Sect. 3, phase scintillation events lasting several minutes are more frequent in the cusp when compared to nightside auroral oval. The map in Fig. 5d shows the number of scintillation events lasting longer than $3 \mathrm{~min}$ as a function of MLT and CGM latitude. It shows clear preponderance of long-duration events in the cusp. Considering all events re- gardless of their duration, we obtain a very similar map (not shown) for number of scintillation events that occurred concurrently at more than 1 PRN. The map shows the number of such events ranging between 500 and 900 events (each PRN is counted as separate event) in several grid cells in the cusp, while the numbers just exceed 100 in only a few auroral cells. Finally, Fig. 5e shows the duration distributions of cusp and auroral scintillation events for two sectors outlined by dashed rectangles in Fig. 5b. Darker shading shows events observed concurrently at 2 or more PRNs. The event counts shown at 0 min represent total numbers of one-minute parts of all events minus the sum of events 1 min or longer. Ratios of cusp to auroral counts normalized by the total number of data points (broken lines) show increases towards longer durations.

To characterize the auroral and cusp disturbances due to ionospheric currents, a maximum relative (peak-to-peak) change of the horizontal magnetic component in 10-min interval is used as a simple measure of the $\mathrm{H}$-component perturbation observed at each magnetometer location. The mean value of the perturbation as a function of MLT and CGM latitude over two years is shown in Fig. 5c. The magnetometers used are located in Eureka (EUA), Thule (THL), Resolute Bay (RES), Nord (NRD), Taloyoak (TAL), Cambridge Bay (CBB), Baker Lake (BLC), Iqaluit (IQA), Yellowknife (YKC), Fort Churchill (FCC), Sanikiluaq (SNK), Fort McMurray (MCM), Meanook (MEA), Brandon (BRD), Ottawa (OTT), Victoria (VIC) and St. John's (STJ). The phase scintillation enhancements (Fig. 5b) are approximately colocated with regions of enhanced perturbation of the ground magnetic field $\mathrm{H}$-component in the nightside auroral oval and cusp. There are small enhancements of scintillation in the polar cap but there is no evidence in our data of enhanced $\sigma_{\phi}$ in the subauroral region or equatorward of the main trough. The dayside subauroral, auroral and cusp enhancements in TEC are most likely associated with the tongue of ionization (Sojka et al., 1994) and/or sudden enhancement of density (SED) particularly during disturbed periods (Foster et al., 2005; Foster, 2008). These enhancements of ionospheric density are usually segmented into patches that are a source of scintillation in the cusp and polar cap (Prikryl et al., 2010a, b).

Figure 5b shows clear MLT and magnetic latitude dependence of the occurrence of phase scintillation averaged over two years. To examine the seasonal variation of the scintillation occurrence, the statistics are divided into four 3-month intervals that are approximately centered on equinoxes and solstices. Figure 6a-d shows polar maps of the phase scintillation occurrence ( $\sigma_{\phi}$ exceeding 0.1 radians) with 12:00 MLT at the top. The scintillation in the cusp is observed in all seasons but most frequently in winter and predominantly in the pre-noon hours. The scintillation occurrence in auroral oval is highest in autumn and spring and shows a clear dawn-dusk asymmetry (predominance in pre-midnight hours) in all seasons. 


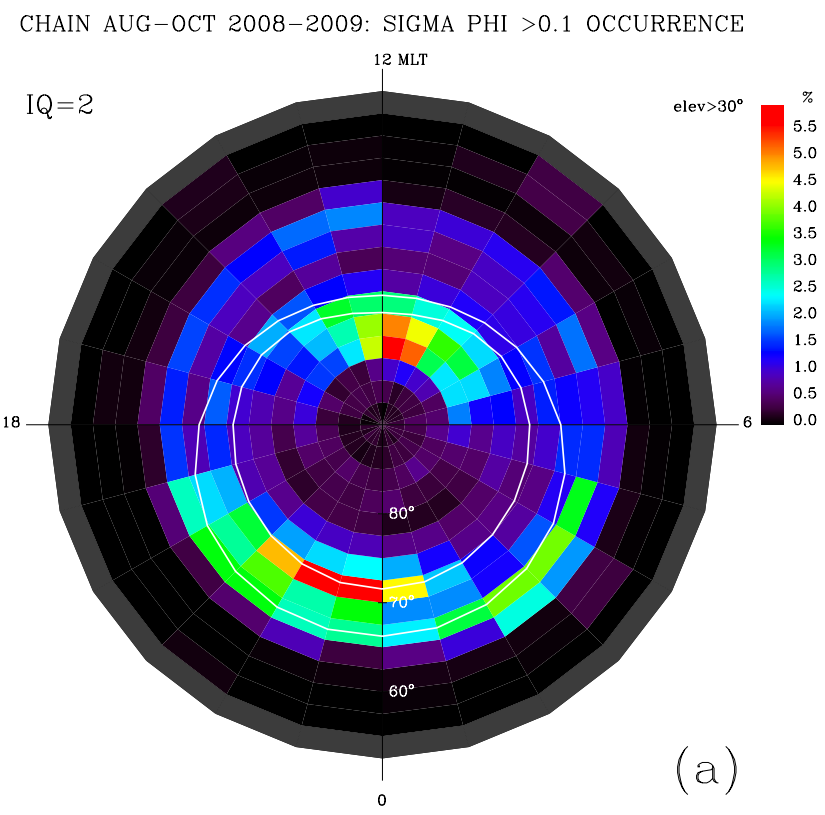

CHAIN FEB-APR 2008-2009: SIGMA PHI >0.1 OCCURRENCE

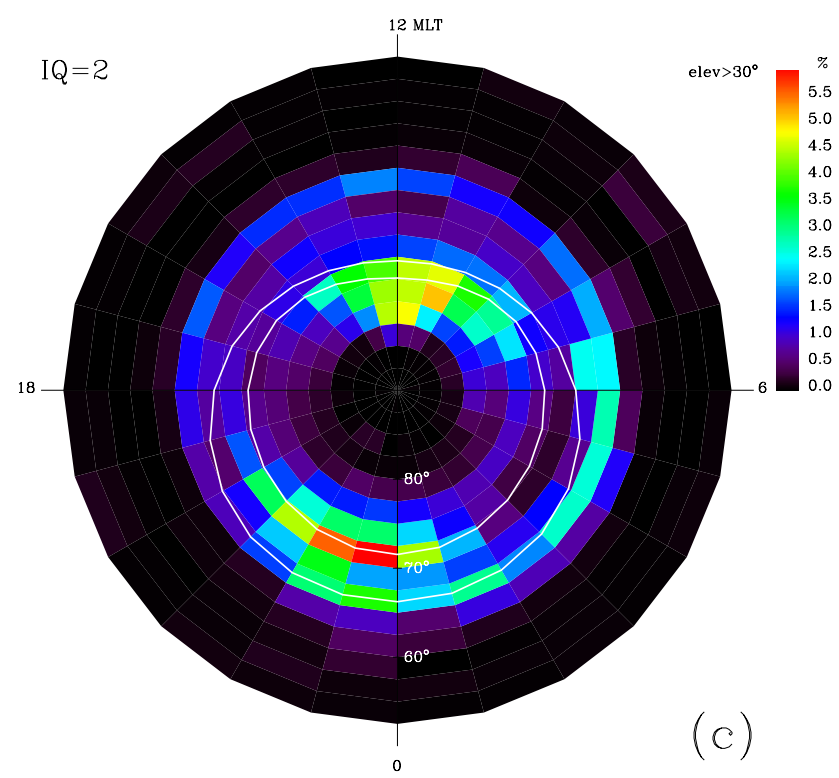

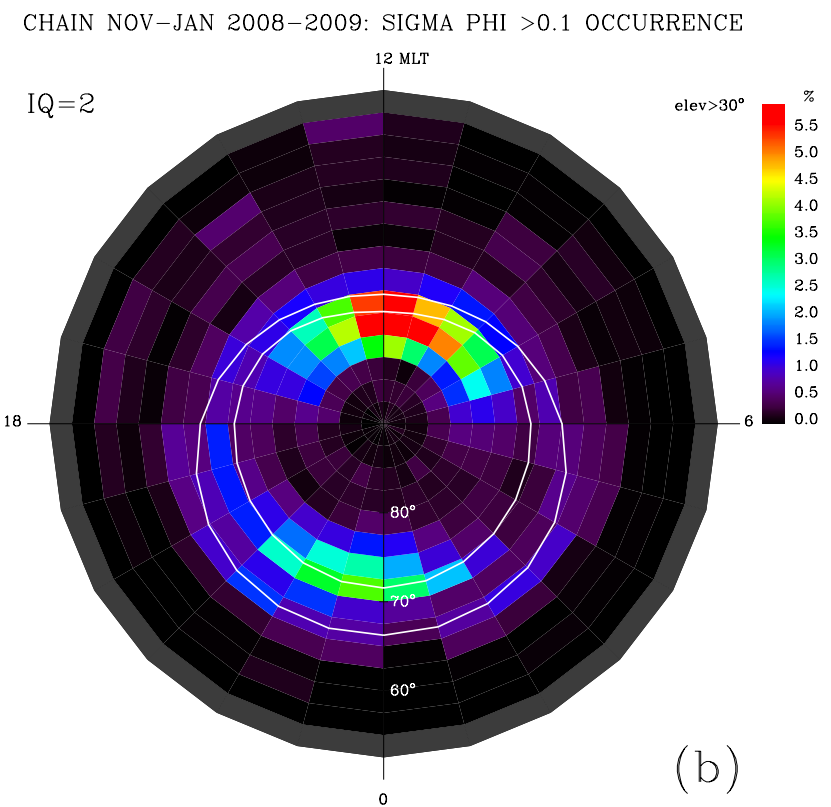

CHAIN MAY-JUL 2008-2009: SIGMA PHI >0.1 OCCURRENCE

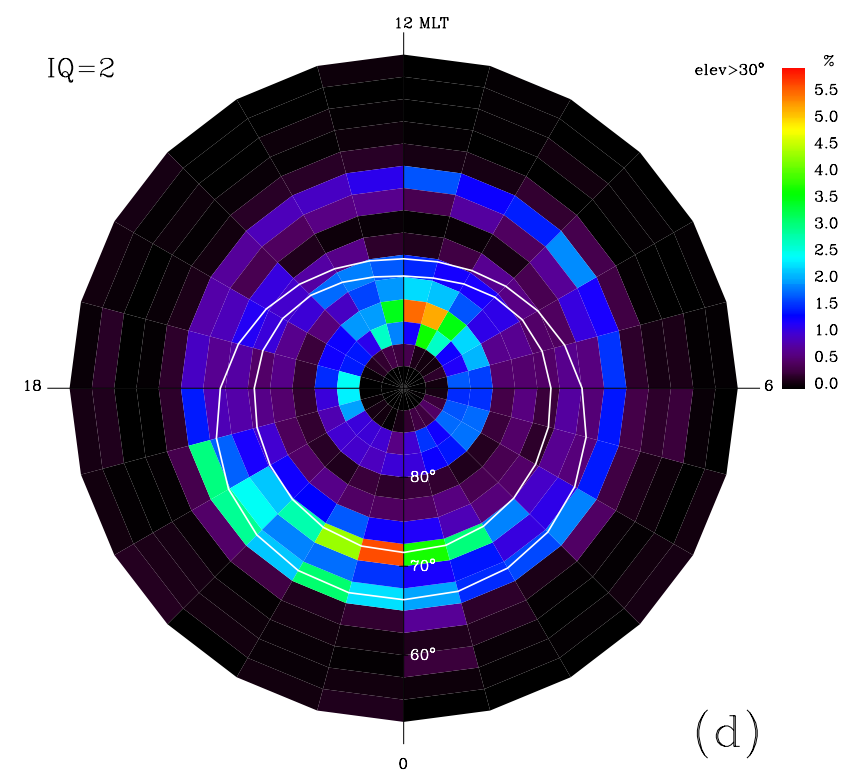

Fig. 6. Phase scintillation climatology maps for (a) autumn, (b) winter, (c) spring and (d) summer. Superposed in white line is the Feldstein oval for $I Q=2$.

To better resolve differences in seasonal dependence of scintillation in the cusp and auroral oval, the data were grouped by months and averaged over two sectors defined by CGM latitude and MLT as indicated by grey dashed rectangles in Fig. 5b. The cusp scintillation sector stretches approximately between 08:00 and 15:00 MLT and $75^{\circ}$ and $82.5^{\circ} \mathrm{CGM}$ latitude, and most of the nightside auroral scintillation lies between 19:00 and 02:00 MLT and $65^{\circ}$ and $75^{\circ} \mathrm{CGM}$ latitude. Figure 7 a shows the seasonal variations of phase scintillation occurrence in the cusp and nightside auroral oval. The auroral scintillation shows an expected semi- annual oscillation with equinoctial maxima known to be associated with aurorae. The maxima can also be seen in the occurrence of ground magnetic perturbation $>30 \mathrm{nT}$ for the nightside auroral (Fig. 7b) although the autumnal maximum appears to be less pronounced. In the cusp, phase scintillation is dominated by an annual cycle with scintillation occurrence being lowest in summer months and highest in autumn to winter months. The cusp ground magnetic perturbations are produced by ionospheric currents that depend on conductivity which is highest in summer. 

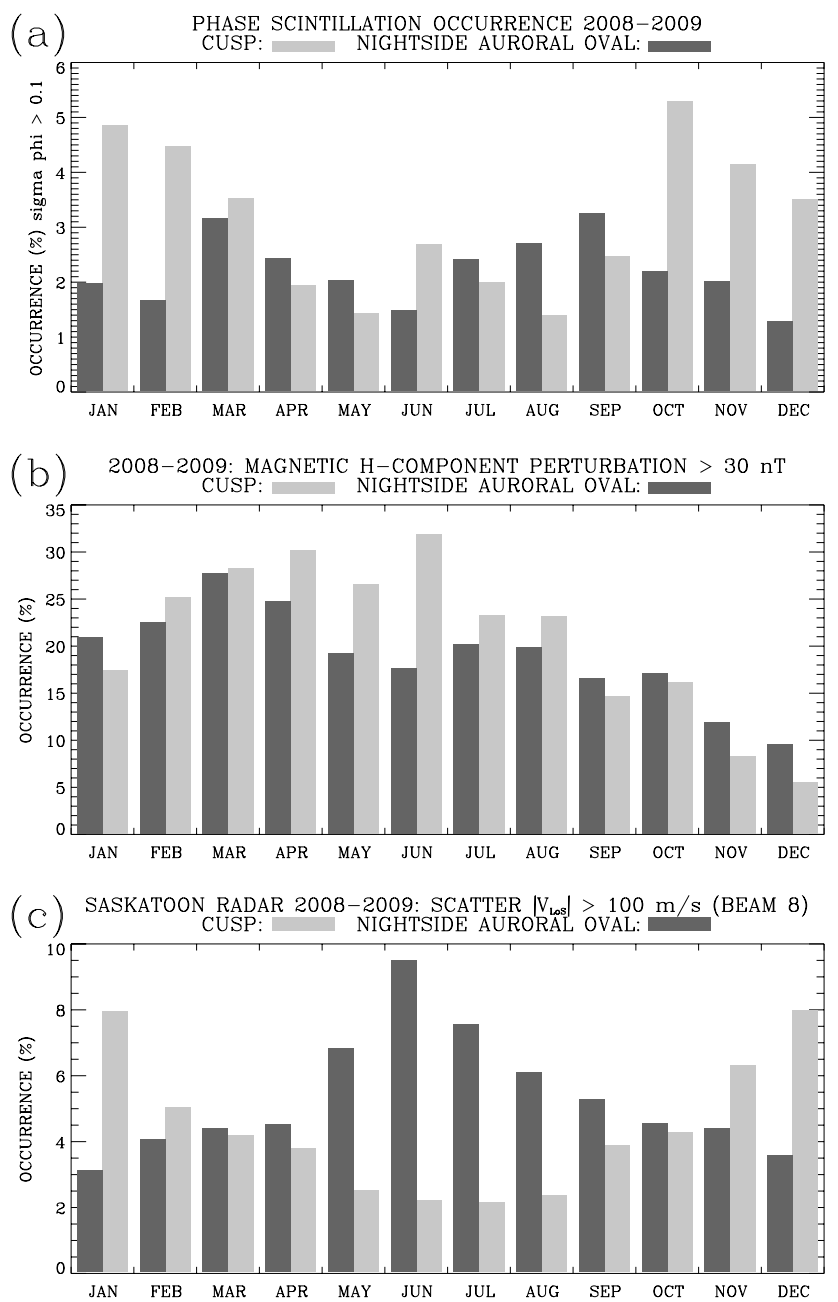

Fig. 7. Seasonal variation in the cusp and nightside auroral oval of the occurrence of (a) phase scintillation $\sigma_{\phi}>0.1$ radians, (b) ground magnetic perturbation $>30 \mathrm{nT}$, and (c) the F-region ionospheric radar backscatter with LoS velocity exceeding $100 \mathrm{~m} \mathrm{~s}^{-1}$.

So far, CHAIN has operated during very quiet solar and geomagnetic conditions, except for some moderately disturbed periods when phase scintillation was significantly enhanced. To discriminate between very quiet and moderately active periods the scintillation statistics are divided into two parts by 3-hourly Kp index level over $24 \mathrm{~h}$ (Fig. $8 \mathrm{a}$ and b). A disturbed day is defined as having a 3-hourly $\mathrm{Kp}$ index greater than 2 for more than $60 \%$ of the day. Even such low threshold value gives relatively sparse statistics of moderately disturbed days. Nevertheless, there is a significant equatorward shift of about $2.5^{\circ}$ in latitude (one latitude cell) of the scintillation regions in the cusp and auroral oval when $\mathrm{Kp}$ index is elevated. In general, the occurrence of phase scintillation significantly increases in these regions. Also, there is moderate enhancement of scintillation equatorward of the statistical oval on the dayside. This enhancement may be attributed either to equatorward shift of the cusp or to more frequent SED events during disturbed periods.
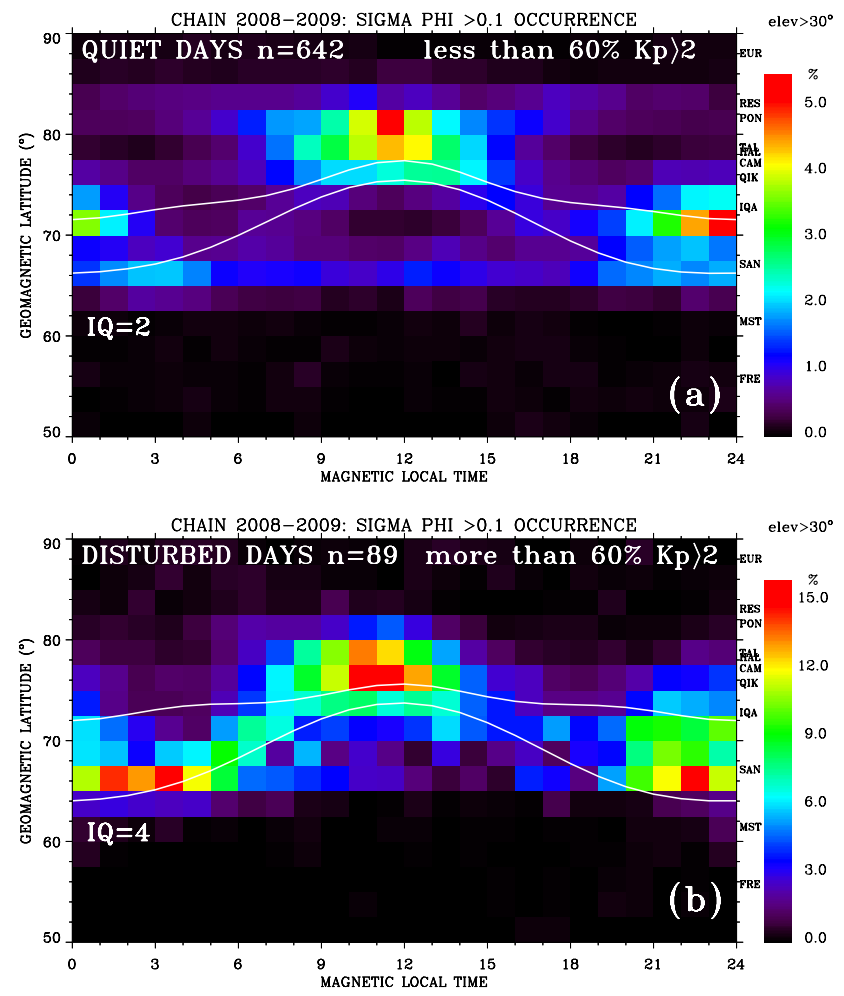

Fig. 8. Phase scintillation maps for geomagnetically (a) quiet and (b) disturbed days. Note different color scales.

\section{HF radar backscatter climatology}

Scintillation is caused by ionospheric irregularities of scale sizes from hundreds of meters to a few kilometers. These larger irregularities may coexist with small-scale fieldaligned irregularities produced by plasma instabilities such as the gradient-drift instability. Using multifrequency scintillation and 50-MHz radar observations Basu et al. (1978) studied such coexistence of large- and small-scale irregularities in the nighttime equatorial F-region. HF radar backscatter from decameter-size irregularities drifting with $\boldsymbol{E} \times \boldsymbol{B}$ velocity is routinely observed with SuperDARN. Figure 9 a shows the mean occurrence of ionospheric backscatter with line-of-sight velocities exceeding $100 \mathrm{~m} \mathrm{~s}^{-1}$ observed by the Saskatoon radar beam 8 averaged and mapped into bins of $1 \mathrm{~h}$ MLT $\times 1.5^{\circ}$ CGM latitude for geomagnetically quiet days in 2008-2009. For comparison of the HF backscatter with phase scintillation occurrence, the irregularity drift is important since the phase scintillation is expected to be closely linked to the magnitude of relative motion of the irregularity and its variability. The F-region backscatter tracks well the statistical auroral oval that is shown for relatively quiet conditions $(\mathrm{IQ}=2)$. The highest occurrence of $\mathrm{HF}$ radar backscatter is in the post noon and pre-midnight auroral oval including the E-region backscatter (range $<800 \mathrm{~km}$ or CGM latitude less than $67^{\circ}$ ). Around 12:00 MLT the occurrence 

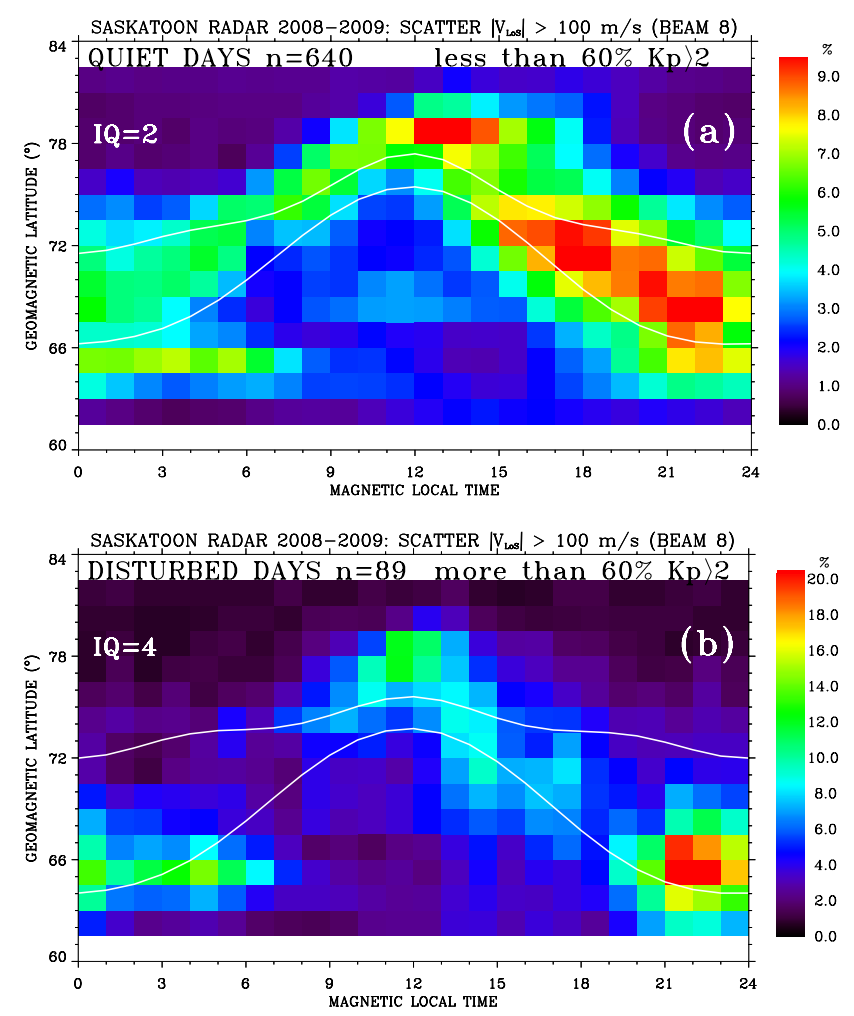

Fig. 9. The occurrence of E- and F-region ionospheric backscatter with absolute value of LoS velocity exceeding $100 \mathrm{~m} \mathrm{~s}^{-1}$ observed by the Saskatoon radar beam 8 during geomagnetically (a) quiet and (b) moderately disturbed days.

of HF radar backscatter is enhanced poleward of the oval in the cusp/cleft (above $\sim 75^{\circ} \mathrm{CGM}$ latitude). For moderately disturbed days (Fig. 9b) the backscatter in the nightside auroral oval is almost twice as frequent as it appears during quiet days and the backscatter regions shift equatorward showing a clear predominance of occurrence rate in the pre-midnight sector. These relative enhancements in occurrence of drifting irregularities in the cusp and pre-midnight oval agree well with the phase scintillation occurrence (Fig. 8a and b).

Figure 10 shows the radar backscatter statistics grouped into 3-month periods that are approximately centered about the equinoxes or solstices. As seen in Fig. 6 for phase scintillation, the backscatter occurrence in the cusp region is highest in winter (exceeding 15\%) but is reduced to less than half of that in other seasons. The F-region auroral backscatter is detected primarily in the pre-midnight sector in all seasons but the occurrence is highest in the dusk sector in summer. To compare the seasonal variation of backscatter occurrence in the cusp and in the nightside auroral oval we use the same time intervals and approximately the same latitude intervals as for scintillation (Fig. 5b) to define the backscatter sectors. Figure $7 \mathrm{c}$ shows the seasonal variations of ionospheric backscatter occurrence in the cusp and nightside auroral oval. Similarly to phase scintillation (Fig. 7a) the cusp backscatter in Fig. 7c is showing annual cycle with a minimum in summer and maximum in winter. The nightside auroral backscatter occurrence has a minimum in winter but unlike the phase scintillation it shows a large maximum in summer months, which is due to more favorable HF propagation condition in a dense ionosphere that refracts the radio waves to perpendicularity with the magnetic field at near ranges from the radar (see, Sect. 6). This annual variation due to propagation conditions almost completely masks the semiannual oscillation due to aurora occurrence, although the plateaus in the monthly occurrence distribution near the equinoxes are suggestive of superposed equinoctial enhancements.

\section{Anisotropy of ionospheric irregularities}

Small scale ionospheric irregularities such as those detected as backscatter by HF radars are closely aligned with magnetic field lines. However, the anisotropy is size-dependent and larger irregularities are less elongated than smaller ones (Fremouw et al., 1985; Wernik et al., 1990). VHF and UHF scintillation measurements at high latitudes (Rino and Owen, 1980; Livingston et al., 1982; Gola et al., 1992) suggested a range of axial ratios to characterize irregularity shapes. The elongated and closely field-aligned cylindrical irregularities and shorter elongated rod-like irregularities have one axis of symmetry described by axial ratio $a: 1: 1$. Sheet-like ( $a: a: 1)$ and non-symmetrical wing-like ( $a: b: 1$, where $a>b$ ) structures are elongated along surfaces of constant magnetic latitude (L-shells). The values of $a$ are typically between 3 and 15 and $b<3$ (Livingston et al., 1982; Gola et al., 1992). Gola et al. (1992) showed maps of an amplitude scintillation index as a function of angles between the ray path and the geomagnetic L-shell and the plane of magnetic meridian at an altitude of $350 \mathrm{~km}$ indicating a predominance of field-aligned irregularities. Their VHF amplitude scintillation index showed enhanced values in the magnetic zenith particularly in the magnetic nighttime sector and for high geomagnetic activity.

Figure 11 shows GPS phase scintillation occurrence as a function of off-meridian and off-shell angles that were determined for receiver-satellite ray at the $350-\mathrm{km}$ ionospheric pierce point. The data are binned into $5 \times 5^{\circ}$ grid points with the off-shell angle positive for IPPs northward of receiver and off-meridian angle positive for IPPs eastward of receiver. The angle distribution map for all MLTs and latitudes combined (Fig. 11a) shows that phase scintillation predominantly occurred at low off-shell angles less than $20^{\circ}$ with highest percentages at off-meridian angles $\pm 30^{\circ}$ and particularly near the magnetic zenith. This suggests that scintillation is caused by a mixture of field-aligned and L-shelloriented irregularities. Figure 11c and d shows the distribution maps for the cusp and nightside auroral oval sectors as defined in Fig. 5b. The scintillation causing irregularities appear to be more shell-aligned in the cusp than in the nightside 

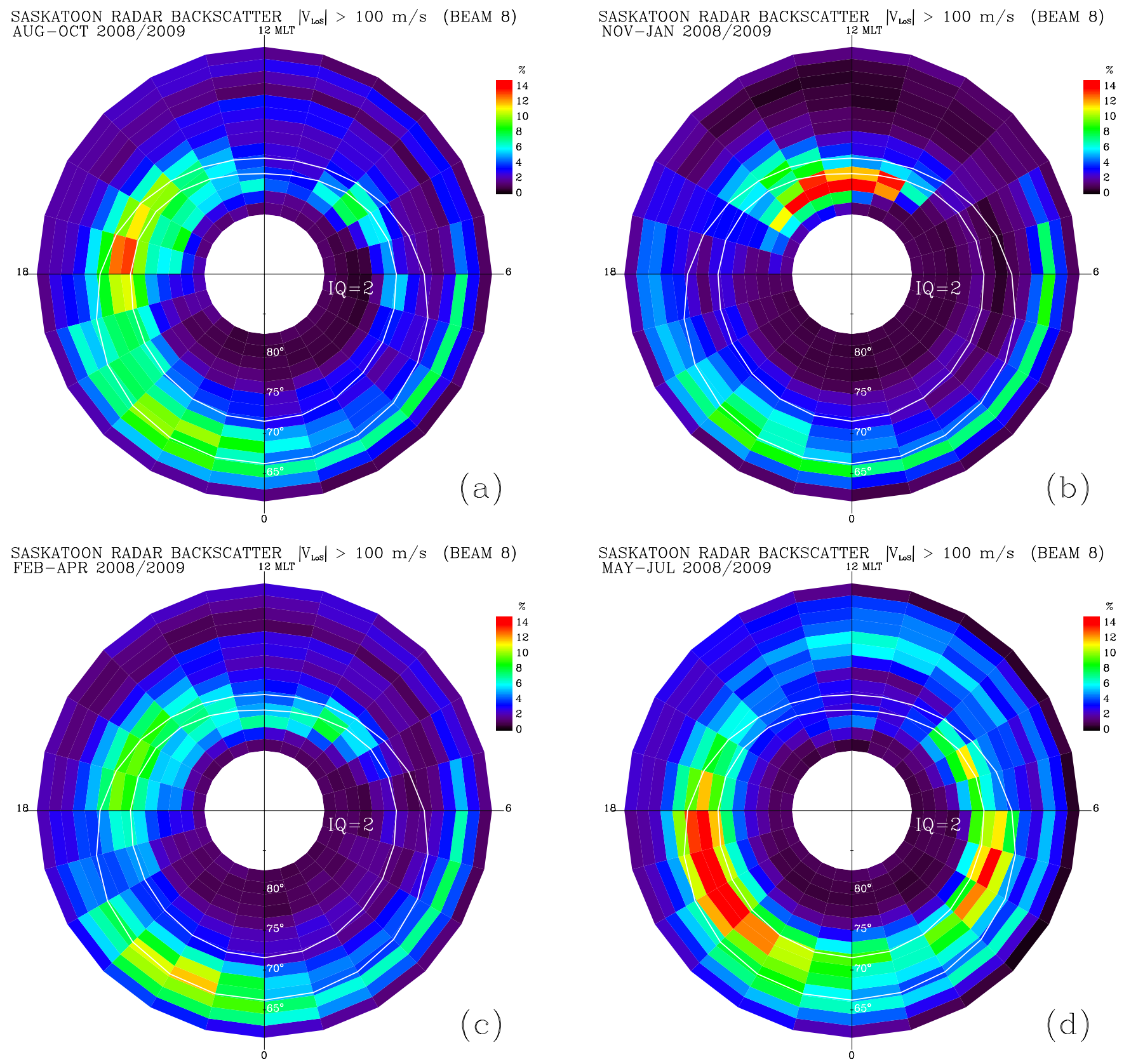

Fig. 10. The ionospheric backscatter occurrence observed with the Saskatoon radar beam 8 in (a) autumn, (b) winter, (c) spring and (d) summer. Superposed in white line is the Feldstein oval for IQ $=2$.

auroral oval where there was higher percentage of scintillation near magnetic zenith suggesting field-aligned irregularities. The scintillation percentages increased significantly with geomagnetic activity particularly for angles near the magnetic zenith both in the cusp and auroral oval (Fig. 11e and f). At cusp latitudes the observations are mostly confined to the south of the receiver and are scarce close to magnetic zenith, completely missing poleward of it. Enhanced scintillation was observed at low off-shell angles but across a wide range of off-meridian angles, which points to $\mathrm{L}$-shell aligned irregularities. Figure $11 \mathrm{~b}$ summarizes the anisotropy results by showing scintillation occurrence averaged over a range of off-meridian $\left( \pm 40^{\circ}\right)$ and off-shell (from $-20^{\circ}$ to $+10^{\circ}$ ) angles to compare relative alignment with $\mathrm{L}$-shell (broken lines) and meridian (solid lines), respectively, in the cusp and nightside auroral oval for all days as well as for geomagnetically disturbed days. The sharpest peaks are found for mean scintillation occurrence as a function of off-shell angle suggesting predominantly L-shell alignment. However, concurrent peaks at small off-meridian angles (solid lines) indicate field-aligned irregularities during disturbed conditions both in the cusp and auroral oval. 

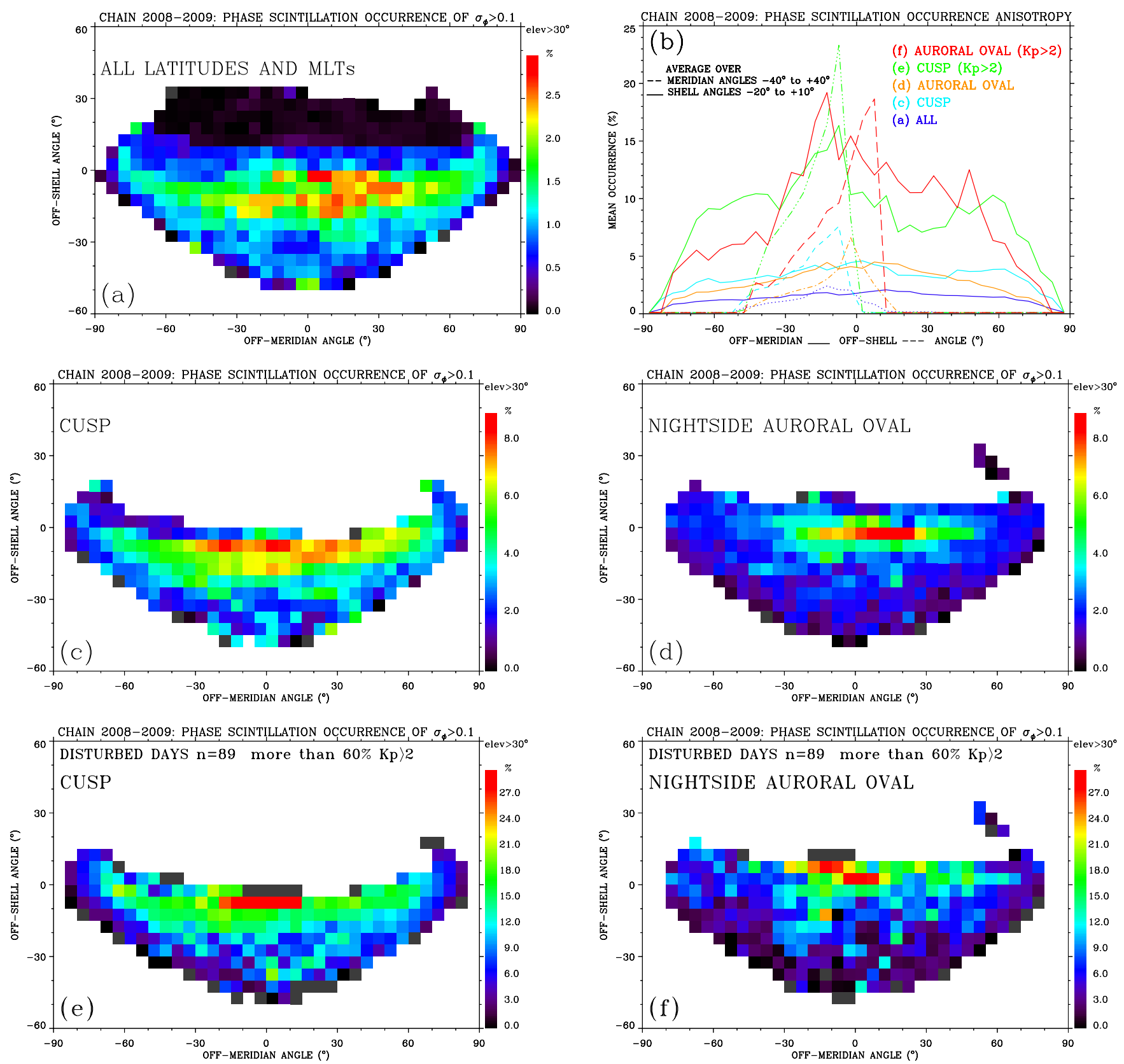

Fig. 11. Maps of phase scintillation occurrence as a function of off-meridian and off-shell angles for data from (a) all latitudes and MLTs combined, (c) cusp sector and (d) nightside auroral oval. The maps for disturbed days are shown for (e) cusp and (f) nightside auroral oval sectors separately. (b) Average scintillation occurrence profiles perpendicularly to magnetic meridian (solid lines) and L-shell (broken lines) are shown for each map.

\section{Discussion}

At high latitudes, phase scintillation index $\sigma_{\phi}$ often has higher values than the amplitude scintillation index $S_{4}$. This is particularly the case at GPS frequencies, when amplitude scintillation may be completely absent in the presence of phase scintillation (Basu et al., 1998; Doherty et al., 2000; $\mathrm{Li}$ et al., 2010). This is sometimes attributed to improper detrending of GPS data as already mentioned at the end of
Sect. 3. Consistent with UHF scintillation (Kersley et al., 1995), GPS phase scintillation occurrence at cusp latitudes showed seasonal variation with a maximum between late autumn and early winter months (Li et al., 2010). These authors also reported the diurnal variation of phase scintillation and its dependence on IMF at both northern and southern cusp locations. In the polar cap, Prikryl et al. (2010a, b) found seasonal and hourly dependencies of GPS phase scintillation and TEC. The occurrence statistics of the parameters 
were similar to seasonal and hourly dependencies of polar cap patches as observed in F-region ionosonde echoes and HF radar backscatter. Such behaviour agrees with models of the patch-to-background $N m \mathrm{~F} 2$ ratio by Sojka et al. (1994).

The mapping of scintillation occurrence as a function of magnetic latitude and MLT was done previously for GPS receiver arrays in the European sector using data from October to December 2003 that also showed low $S_{4}$-index level at high latitudes (Spogli et al., 2009). The present paper extends the period to two years around the solar minimum while improving the spatial coverage and resolution over the NorthAmerican sector. The mean TEC as a function of magnetic latitude and MLT shows TEC depletions associated with statistical mid- and high-latitude F-region ionization troughs (Muldrew, 1965) and large enhancements in TEC (statistical tongue of ionization) on the dayside extending through the cusp into the polar cap. A clear statistical link between the phase scintillation occurrence and geomagnetic activity is found. The enhanced cusp and auroral scintillation enhancements shift in latitude with the level of geomagnetic activity. However, no statistical enhancement of phase scintillation at the equatorward border of the main trough (Spogli et al., 2009) has been found in CHAIN data from 2008-2009. Also, only a weak mean occurrence of phase scintillation is found in the polar cap. However, it is expected that scintillation due to polar patches and polar cap aurorae will increase with the rise of solar activity in the current solar cycle as was already demonstrated by a few ionospheric events in 20092010 (Prikryl et al., 2010b).

We identified important differences between the cusp and nightside auroral oval in the localization and intermittency of phase scintillation events, scintillation duration distribution and seasonal variation. The nightside scintillation tends to be more intermittent and localized to auroral arc brightening events. The scintillation in the cusp/cleft sector shows an excess of long-duration events and multiple PRN events, suggesting that it is more continuous and can persist over a large geographical area for several hours. These differences may point to different scintillation-causing irregularity production mechanisms: energetic electron precipitation into dynamic auroral arcs versus cusp ionospheric convection dynamics. Anisotropy of irregularity shape that is found both in the cusp and nightside auroral oval suggests that the irregularities causing phase scintillation in the cusp are more strongly aligned with magnetic L-shells whereas in the nightside auroral oval the scintillation occurrence as a function of offshell and off-meridian angles suggests more significant component of field-aligned irregularities. This is consistent with expectation of largely precipitation-driven auroral irregularities and convection-driven cusp irregularities. In the cusp, L-shell aligned flow channel events frequently shape the density structure by producing density depletions with steep gradients perpendicularly to L-shell (Rodger et al., 1994; Prikryl et al., 1999).
Phase scintillation in the nightside auroral oval shows a clear semiannual variation maximizing in equinoxes, which is similar to what is expected for aurorae and to what is found for geomagnetic activity. On the other hand, the cusp scintillation is dominated by an annual cycle maximizing in late autumn and in winter with lower occurrence in spring and summer. A comparison between the occurrence of phase scintillation and HF radar backscatter from fieldaligned irregularities is addressing the question of coexistence of kilometer- and meter-scale irregularities, which was first raised for equatorial latitudes (Basu et al., 1978) and followed up at high latitudes (Milan et al., 2005). We found a statistical collocation of the phase scintillation and HF radar backscatter occurrence in the auroral oval and cusp.

It should be noted that the HF backscatter occurrence at high latitudes is strongly dependent on HF radio wave propagation in addition to the presence of ionospheric irregularities themselves (Milan et al., 1997; Parkinson et al., 2003). Solar illumination controls the E- and F-region electron density and the HF propagation modes. Thus the location and occurrence of the backscatter varies with season. During summer months, when the dense ionosphere easily refracts the radio wave towards perpedicularity with the magnetic field, the HF backscatter occurrence is highest and predominantly at near-to-mid ranges in the nightside auroral oval. Around the winter solstice, ionospheric backscatter occurs preferentially at higher latitudes and peaks in the cusp, on the day side near noon. For the months before and after the winter solstice, towards and eventually past both equinoxes, auroral backscatter gradually strengthens and shifts to lower latitudes (near ranges), away from noon and towards the midnight sector. Around the summer solstice, auroral backscatter occurrence maximizes in both the post- and pre-midnight sectors. This is a consequence of changing HF propagation conditions. However, at the same time, midnight/premidnight backscatter that is associated with GPS phase scintillation persists at all seasons. It appears to be distinct from the HF-propagation-induced enhancements in the dusk and dawn sectors, although in summer the dusk enhancement due to propagation effect overlaps with the persisting component of the backscatter in the pre-midnight sector. It should be noted that the overlap between the phase scintillation and HF backscatter in the midnight/pre-midnight sector is best seen at the equatorward edge of the auroral oval. At higher auroral latitudes, where the scintillation occurrence is enhanced in all seasons (Fig. 6), the HF backscatter is reduced (Fig. 10).

\section{Summary and conclusions}

The data from the first two years of operation of CHAIN have been analyzed to develop the climatology of GPS phase scintillation at high latitudes. During the period of 20082009 that coincided with a deep solar minimum, the amplitude scintillation $\left(S_{4}\right.$ index) remained insignificant but strong 
phase scintillation events frequently occurred. In the nightside auroral oval the phase scintillation was associated with auroral arc brightening and auroral substorms. Around local noon, the phase scintillation occurred in the cusp ionosphere that is perturbed by intense and dynamic convection. Some characteristics of phase scintillation occurrence were different in the nightside auroral oval comparing to those found in the cusp. The phase scintillation in the nightside tended to be more intermittent, localized and of short duration than in the cusp. The dayside scintillation individual events sometimes lasted for several minutes per satellite and scintillation persisted over a large area of the cusp/cleft region sampled by different satellites for several hours.

The occurrence of GPS phase scintillation observed by CHAIN at high latitudes has been compared with the occurrence of HF radar backscatter from $\boldsymbol{E} \times \boldsymbol{B}$ drifting fieldaligned irregularities observed by SuperDARN. The phase scintillation and F-region HF backscatter as a function of magnetic local time and geomagnetic latitude primarily occur in the nighttime auroral oval and in the ionospheric cusp. Subset maps for geomagnetically quiet and moderately disturbed periods show expected shifts in latitude of the ionospheric regions both in the occurrence of phase scintillation and the HF radar backscatter. F-region backscatter occurrence is strongly dependent on HF propagation and thus primarily controlled by annual cycle of solar illumination of the ionosphere. Auroral scintillation occurrence shows semiannual variation with maxima around equinoxes. In the cusp, scintillation occurrence is dominated by an annual cycle maximizing in autumn-winter. The differences between the auroral and cusp scintillation occurrence point to different scintillation-causing irregularity production mechanisms: energetic electron precipitation into dynamic auroral arcs versus cusp ionospheric convection dynamics. This is consistent with observations of anisotropy of the scintillation-causing irregularities suggesting predominantly L-shell aligned irregularities in the cusp while a significant component of field-aligned irregularities is found in the nigthtside auroral oval.

Acknowledgements. Infrastructure funding for CHAIN was provided by the Canada Foundation for Innovation and the New Brunswick Innovation Foundation. CHAIN and CGSM operation is conducted in collaboration with the Canadian Space Agency (CSA). The funding for the operation of SuperDARN radars in Saskatoon and Rankin Inlet was provided by the Natural Sciences and Engineering Research Council of Canada (NSERC) and CSA. The results presented in this paper rely on data collected at magnetic observatories operated by the Canadian GeoSpace Monitoring network, the Geological Survey of Canada and the Danish Meteorological Institute. We thank the national institutes that support those agencies and to INTERMAGNET for providing magnetometer data (www.intermagnet.org).

Topical Editor P.-L. Blelly thanks L. Alfonsi and another anonymous referee for their help in evaluating this paper.

\section{References}

Aarons, J.: Global morphology of ionospheric scintillations, Proceedings of IEE, 70(4), 360-378, 1982.

Aarons, J.: Global positioning system phase fluctuations at auroral latitudes, J. Geophys. Res., 102(A8), 17219-17231, doi:10.1029/97JA01118, 1997.

Aarons, J., Lin, B., Mendillo, M., Liou, K., and Codrescu, M.: Global Positioning System phase fluctuations and ultraviolet images from the Polar satellite, J. Geophys. Res., 105(A3), 52015213, doi:10.1029/1999JA900409, 2000.

Alfonsi, L., Kavanagh, A., Amata, E., Cilliers, P., Correia, E., Freeman, M., Kauristie, K., Liu, R., Luntama, J. P., Mitchell, C. N., and Zherebtsov, G. A.: Probing the high latitude ionosphere from ground-based observations: The state of current knowledge and capabilities during IPY (2007-2009), J. Atmos. Solar-Terr. Phys., 70(18), 2293-2308, 2008.

Baker, K. B. and Wing, S.: A new magnetic coordinate system for conjugate studies at high latitudes, J. Geophys. Res., 94, 91399143, 1989.

Baker, K. B., Dudeney, J. R., Greenwald, R. A., Pinnock, M., Newell, P. T., Rodger, A. S., Mattin, N., and Meng, C.-I.: HF radar signatures of the cusp and low-latitude boundary layer, J. Geophys. Res., 100, 7671-7695, 1995.

Basu, Su.: Universal time seasonal variations of Auroral Zone magnetic activity and VHF scintillations, J. Geophys. Res., 80(34), 4275-4728, 1975.

Basu, S., Basu, S., Aarons, J., McClure, J. P., and Cousins, M. D.: On the Coexistence of Kilometer- and Meter-Scale Irregularities in the Nighttime Equatorial $F$ Region, J. Geophys. Res., 83(A9), 4219-4226, doi:10.1029/JA083iA09p04219, 1978.

Basu, S., MacKenzie, E. M., Basu, Su., Costa, E., Fougere, P. F., Carson Jr., H. C., and Whitney, H. E.: $250 \mathrm{MHz} / \mathrm{GHz}$ scintillation parameters in the equatorial, polar, and auroral environments, IEEE Journal on Selected Areas in Communications, SAC-2(2), 102-115, 1987.

Basu, S., Basu, S., Sojka, J. J., Schunk, R. W., and MacKenzie, E.: Macroscale modeling and mesoscale observations of plasma density structures in the polar cap, Geophys. Res. Lett., 22(8), 881-884, doi:10.1029/95GL00467, 1995.

Basu, S., Weber, E. J., Bullett, T. W., Keskinen, M. J., MacKenzie, E., Doherty, P., Sheehan, R., Kuenzler, H., Ning, P., and Bongiolatti, J.: Characteristics of plasma structuring in the cusp/cleft region at Svalbard, Radio Sci., 33(6), 1885-1899, doi:10.1029/98RS01597, 1998.

Chisham, G., Lester, M., Milan, S. E., Freeman, M. P., Bristow, W. A., Grocott, A., McWilliams, K. A., Ruohoniemi, J. M., Yeoman, T. K., Dyson, P. L., Greenwald, R. A., Kikuchi, T., Pinnock, M., Rash, J. P. S., Sato, N., Sofko, G. J., Villain J.-P., and Walker, A. D. M.: A decade of the Super Dual Auroral Radar Network (SuperDARN): scientific achievements, new techniques and future directions, Surv. Geophys, 28, 33-109, doi:10.1007/s10712007-9017-8, 2007.

Doherty, P. H., Delay, S. H., Valladares, C. E., and Klobuchar, J. A.: Ionospheric scintillation effects in the equatorial and auroral regions, in: Proceedings of the 13th International Technical Meeting of the Satellite Division of the Institute of Navigation ION GPS 2000, Salt Lake City, USA, 19-22 September 2000, 662-671, 2000.

Donovan, E., Trondsen, T., Cogger, L., and Jackel, B.: Auro- 
ral imaging within the Canadian CANOPUS and NORSTAR projects, Sodankylä Geophysical Observatory Publications, 92, 109-112, 2003.

Feldstein, Y. I. and Starkov, G. V.: Dynamics of auroral belt and polar geomagnetic disturbances, Planet. Space Sci., 15, 209-230, 1967.

Forte, B.: Optimum detrending of raw GPS data for scintillation measurements at auroral latitudes, J. Atoms. Solar Terr. Phys., 67, 1100-1109, doi:10.1016/j.jastp.2005.01.011, 2005.

Forte, B.: On the relationship between the geometrical control of scintillation indices and the data detrending problems observed at high latitudes, Annals of Geophysics, 50(N6), 699-706, 2007.

Forte, B. and Radicella, S. M.: Problems in data treatment for ionospheric scintillation measurements, Radio Sci., 37(6), 1096, doi:10.1029/2001RS002508, 2002.

Foster, J. C.: Ionospheric-Magnetospheric-Heliospheric Coupling: Storm-Time Thermal Plasma Redistribution, Midlatitude Ionospheric Dynamics and Disturbances, Geophysical Monograph Series, 181, 121-134, AGU 2008.

Foster, J. C., Coster, A. J., Erickson, P. J., Holt, J. M., Lind, F. D., Rideout, W., McCready, M., Van Eyken, A., Barnes, R. J., Greenwald, R. A., and Rich, F. J.: Multiradar observations of the polar tongue of ionization, J. Geophys. Res., 110, A09S31, doi:10.1029/2004JA010928, 2005.

Fremouw, E. J., Secan, J. A., and Lansinger, J. M.: Spectral behavior of phase scintillation in the nighttime auroral region, Radio Sci., 20(4), 923-933, doi:10.1029/RS020i004p00923, 1985.

Gola, M., Wernik, A. W., Franke, S. J., Liu, C. H., and Yeh, K. C.: Behaviour of HILAT scintillation over Spitsbergen, J. Atmos. Terr. Phys., 54(9), 1207-1213, 1992.

Greenwald, R. A., Baker, K. B., Dudeney, J. R., Pinnock, M., Jones, T. B., Thomas, E. C., Villain, J.-P., Cerrisier, J.-C., Senior, C., Hanuise, C., Hunsucker, R. D., Sofko, G., Koehler, J., Nielsen, E., Pellinen, R., Walker, A. D. M., Sato, N., and Yamagishi, H.: DARN/ SUPERDARN A global view of the dynamics of highlatitude convection, Space Sci. Rev., 71, 761-796, 1995.

Hajj, G. A., Wilson, B. D., Wang, C., Pi, X., and Rosen, I. G.: Data assimilation of ground GPS total electron content into a physicsbased ionospheric model by use of the Kalman filter, Radio Sci., 39, RS1S05, doi:10.1029/2002RS002859, 2004.

Holzworth, R. H. and Meng, C.-I.: Mathematical Representation of the Auroral Oval, Geophys. Res. Lett., 2(9), 377-380, 1975.

Jayachandran, P. T., Langley, R. B., MacDougall, J. W., Mushini, S. C., Pokhotelov, D., Hamza, A. M., Mann, I. R., Milling, D. K., Kale, Z. C., Chadwick, R., Kelly, T., Danskin, D. W., and Carrano, C. S.: Canadian High Arctic Ionospheric Network (CHAIN), Radio Sci., 44, RS0A03, doi:10.1029/2008RS004046, 2009.

Kersley, L., Pryse, S. E., and Wheadon, N. S.: Amplitude and phase scintillation at high latitudes over northern Europe, Radio Sci., 23(3), 320-330, 1988.

Kersley, L., Russell, C. D., and Rice, D. L.: Phase scintillation and irregularities in the northern polar ionosphere, Radio Sci., 30(3), 619-629, 1995.

Li, G., Ning, B., Ren, Z., and Hu, L.: Statistics of GPS ionospheric scintillation and irregularities over polar regions at solar minimum, GPS Solutions, doi:10.1007/s10291-009-0156-x, 2010.

Liu, W. W.: Canadian space environment program and international living with a star, Adv. Space Res., 35(1), 51-60, 2005.
Livingston, R. C., Rino, C. L., Owen, J., and Tsunoda, R. T.: The Anisotropy of High-Latitude Nighttime $F$ Region Irregularities, J. Geophys. Res., 87(A12), 10519-10526, doi:10.1029/JA087iA12p10519, 1982.

MacDougall, J. W.: Distribution of irregularities in the northern polar region determined from HILAT observations, Radio Sci., 25(2), 115-124, doi:10.1029/RS025i002p00115, 1990a.

MacDougall, J. W.: The polar-cap scintillation zone, J. Geomag. Geoelectr., 42, 777-788, 1990b.

MacDougall, J. W., Grant, I. F., and Shen, X.: The Canadian Advanced Digital Ionosonde: design and results, in: Report UAG14: Ionospheric Networks and Stations, World Data Center A for Solar-Terrestrial Physics, 21, 1995.

Mann, I., R., Milling, D. K., Rae, I. J., Ozeke, L. G., Kale, A., Kale, Z. C., Murphy, K. R., Parent, A., Usanova, M., Pahud, D. M., Lee, V. Amalraj, E.-A., Wallis, D. D., Angelopoulos, V., Glassmeier, K.-H., Russell, C. T., Auster, H.-U., and Singer, H. J.: The Upgraded CARISMA Magnetometer Array in the THEMIS Era, Space Sci. Rev., 141(1-4), 413-451, doi:10.1007/s11214-0089457-6, 2008.

Milan, S. E., Yeoman, T. K., Lester, M., Thomas, E. C., and Jones, T. B.: Initial backscatter occurrence statistics from the CUTLASS HF radars, Ann. Geophys., 15, 703-718, doi:10.1007/s00585-997-0703-0, 1997.

Milan, S. E., Basu, S., Yeoman, T. K., and Sheehan, R. E.: A comparison of satellite scintillation measurements with HF radar backscatter characteristics, Ann. Geophys., 23, 3451-3455, doi:10.5194/angeo-23-3451-2005, 2005.

Mitchell, C. N. and Spencer, P. S. J.: A three dimensional timedependent algorithm for ionospheric imaging using GPs signals, Annals of Geophysics, 46, 687-696, 2003.

Mitchell, C. N., Alfonsi, L., De Franceschi, G., Lester, M., Romano, V., and Wernik, A. W.: GPS TEC and scintillation measurements from the polar ionosphere during the October 2003 storm, Geophys. Res. Lett., 32, L12S03, doi:10.1029/2004GL021644, 2005.

Muldrew, D. B.: F-layer ionization troughs deduced from Alouette data, J. Geophys. Res., 70(11), 2635-2650, 1965.

Mushini, S. C., Jayachandran, P. T., Langley, R. B., MacDougall, J. W., and Pokhotelov, D.: Improved amplitude and phase scintillation indices derived from wavelet detrended high latitude GPS data, The International Beacon Satellite Symposium BSS2010, edited by: Doherty, P., Hernández-Pajares, M., Juan, J. M., Sanz, J., and Aragon-Angel, A., Campus Nord UPC, Barcelona, 2010.

Ngwira, C. M., McKinnell, L.-A., and Cilliers, P., J.: GPS phase scintillation observed over a high-latitude Antarctic station during solar minimum, J. Atmos. Solar-Terr. Phys., 72(9-10), 718725, 2010.

Parkinson, M. L., Devlin, J. C., Ye, H., Waters, C. L., Dyson, P. L., Breed, A. M., and Morris, R. J.: On the occurrence and motion of decametre-scale irregularities in the sub-auroral, auroral, and polar cap ionosphere, Ann. Geophys., 21, 1847-1868, doi:10.5194/angeo-21-1847-2003, 2003.

Prikryl, P., MacDougall, J. W., Grant, I. F., Steele, D. P., Sofko, G. J., and Greenwald, R. A.: Observations of polar patches generated by solar wind Alfvën wave coupling to the dayside magnetosphere, Ann. Geophys., 17, 463-489, doi:10.1007/s00585999-0463-0, 1999.

Prikryl, P., Jayachandran, P. T., Mushini, S. C., Pokhotelov, D., 
MacDougall, J. W., Donovan, E., Spanswick, E., and St.Maurice, J.-P.: GPS TEC, scintillation and cycle slips observed at high latitudes during solar minimum, Ann. Geophys., 28, 13071316, doi:10.5194/angeo-28-1307-2010, 2010a.

Prikryl, P., Spogli, L., Jayachandran, P. T., Mitchell, C. N., Ning, B., Li, G., Danskin, D. W., Spanswick, E., Donovan, E., Alfonsi, L., De Franceschi, G., and Romano, V.: Inter-hemispheric comparison of GPS phase scintillation at high latitudes during the magnetic-cloud-induced geomagnetic storm of 5-7 April 2010, American Geophysical Union, Fall Meeting Abstract \#SM14A03, 2010b.

Rino, C. L. and Owen, J.: The Structure of Localized Nighttime Auroral Zone Scintillation Enhancements, J. Geophys. Res., 85(A6), 2941-2948, doi:10.1029/JA085iA06p02941, 1980.

Rodger, A. S., Pinnock, M., Dudeney, J. R., Baker, K. B., and Greenwald, R. A.: A new mechanism for polar patch formation, J. Geophys. Res., 99, 6425-6436, 1994.

Sojka, J. J., Bowline, M. D., and Schunk, R. W.: Patches in the polar-cap ionosphere: UT and seasonal dependence, J. Geophys. Res., 99, 14959-14970, 1994.

Spogli, L., Alfonsi, L., De Franceschi, G., Romano, V., Aquino, M. H. O., and Dodson, A.: Climatology of GPS ionospheric scintillations over high and mid-latitude European regions, Ann. Geophys., 27, 3429-3437, doi:10.5194/angeo-27-3429-2009, 2009.
Taylor, J. R.: An introduction to Error Analysis: The Study of Uncertainties in Physical Measurement, 2nd ed., University Science Books, USA, 1997.

Van Dierendonck, A. J. and Arbesser-Rastburg, B.: Measuring ionospheric scintillation in the equatorial region over Africa, including measurements from SBAS geostationary satellite signals, Proceeding of ION GNSS 17th technical meeting of the satellite division, Long Beach, CA, 316, 2004.

Wernik, A. W., Liu, C. H., Franke, S. J., and Gola, M.: High-latitude irregularity spectra deduced from scintillation measurements, Radio Sci., 25(5), 883-895, doi:10.1029/RS025i005p00883, 1990.

Yin, P., Mitchell, C. N., Alfonsi, L., Pinnock, M., Spencer, P., De Franceschi, G., Romano, V., Newell, P., Sarti, P., Negusini, M., and Capra, A.: Imaging of the Antarctic ionosphere: Experimental results, J. Atmos. Solar-Terr. Phys., 71(17-18), 1757-1765, 2009. 